\title{
Biology of Ceroplastes rusci L. (Coccoidea: Lecanidae) on fig tree, Ficus carica L. in the area of Médéa (Algeria)
}

\author{
${ }^{1}$ Biche M Belguendouz R. ${ }^{2}$ Menzer N. and Khouddour $A^{1}$ \\ (1) Laboratoire d'écologie des Vertébrés, Ecole Nationale Supérieure Agronomique, \\ 16200 El-Harrach, Alger - Algérie \\ m.biche@ensa.dz \\ (2) Institut National d'Enseignement Supérieur 09000- Blida (Algérie) \\ rachida2000 dz@yahoo.fr \\ (3) Centre Universitaire de Bordj Bou Arreridj 34000 \\ K malik6@yahoo.fr
}

\begin{abstract}
The biology of C.rusci was studied during an annual cycle on fig tree (Ficus carica) in the area of Médéa (Algeria). This species expresses two generations autumnal and spring. The hivernation is carried out at the stage young female with which they are associated the larvae with the second stage females.
\end{abstract}

Keywords: Ceroplastes rusci, Biology, Oviposition, Fig tree, Algeria

\section{INTRODUCTION}

Ceroplastes rusci is a Mediterranean cochineal, announced for the first time on the Myrtle (Myrtus communis) since highest antiquity. It is called Chinese tortoise, covered with 6-8 waxy plates which protect the body from the insect, frightening on the fig tree in the Mediterranean basin and its adaptation is announced on all Ficus (Balachowsky and Mesnil, 1935). Living on the sheets, branches, branches, it causes the fast deterioration of the fig tree, was propagated in the subtropics, the tropical and Mediterranean areas (Bodenheimer, 1951). It was announced of Italy, Poland and the United Kingdom (Benfatto, 1983) of France (Benassy and Franco, 1974), of Lebanon and Australia (Abel Abounasser, S.D) and of Japan (Silvestri, 1934) on the orange tree. In Algeria (Balachowsky and Mesnil, 1935), in Egypt and in Senegal on the orange tree (Risbec, 1960). Considering the importance of damage caused by this insect with the fig tree we considered to be necessary to lead a study relating initially to the biology of C.rusci to knowing dynamics of the populations, the fruitfulness and the factors of mortality.

\section{MATERIALS AND METHODS}

The area of Médéa $\left(36^{\circ} 16^{\prime} \mathrm{N}-2^{\circ} 45^{\prime} \mathrm{E}\right)$ located in the semi-arid bioclimatic stage at soft winter (Hamadou, 1989), is characterized by one winter cold ( $\mathrm{T}$ minimal average $2.6-3.6^{\circ} \mathrm{C}$ ) and rainy (460 $\mathrm{mm}$ ) and a summer lime and dryness $\left(29^{\circ} \mathrm{C}\right)$.
The study at summer carried out in the area of Médéa ( $800 \mathrm{~m}$ of altitude) between November 2008 and May 2009 in an orchard containing an old plantation of fig tree having a surface of 2.5 hectares which one divided into 10 equal blocks. The prospections were carried out each week on only one tree taken randomly in each block on which one takes four branches of $20 \mathrm{~cm}$ and with a height of $1.50 \mathrm{~m}$. the vegetable material thus collected and treated in laboratory. The cochineals are deducted and classified according to their developmental stage and their states (dead or alive).

\section{RESULTS AND DISCUSSION}

Biological cycle (Fig. 1): At the beginning of our sampling, that is to say the novembre $19^{\text {th }}$, the populations of $C$.rusci were strongly represented by the mobile larvae (93.08\%). Progressively, the manpower of these last will regress until the 25 .décembre to reach $88.5 \%$. At the beginning of March no individual was observed. It is only starting from the end March, that these larvae made their reappearance with $89.7 \%$ of the total population of the cochineal. Of this date and considering the rather rigorous climatic conditions, these individuals were not observed. With regard to the $1^{\text {st }}$ larvae stage, no individual was observed. This is due probably to the climate and the fall of the sheets at the beginning of the autumn. Let us recall that the 
fixing of these larvae is done primarily on the sheets for then migrating towards the branches. The larvae of the second stage female, present irregular variations throughout our study. The minimum is reached on November $19^{\text {th }}$ with $1.8 \%$ and the maximum on February $28^{\text {th }}$ with $100 \%$. These individuals result from the evolution of the 1 st stages of the autumnal period and their migration of the sheets towards the branches with the current of the period October September. The 2st stage male were not observed during the period of our work. We think that these individuals existed apart from our topic.

The Northern orientation seems to be the preferential place for the populations of C.rusci (Fig.2). With our opinion, this exposure is exposed to the dominant winds which blow of south-east and south-west to the current of the autumnal period, period of the migration of the individuals of the sheets towards the branches.

At the beginning of our sampling, the females of C.rusci were in laying. Probably, the laying begins in September and spreads out until the end of December. Indeed, according to our results the maximum is reached on November 25 with 760 eggs and the minimum on December $31^{\text {th }}$ with 81 eggs. Progressively of softening of the temperatures and with the acceleration of ovogenesis, a new laying is noted from March $18^{\text {th }}$. On this date, the average posts 135 eggs. This number will grow until May 11 to reach a maximum of 495 eggs. Taking into account the potential of laying at C.rusci and the results obtained, we think that, the period of oviposition will be spread out still more and the median number of eggs will grow considerably.

The biology of C.rusci at summer already studied by various researchers in particular Bodenheimer (1951) in Israel on the plane tree and Bonnemaison (1953) in France on fig tree and Italy recently by Benfato (1983) on orange tree. In our case, the C.rusci study expressed two generations in the area of Médéa: autumnal and spring. The hivernation is made at the stage young female and adult female associated with the larvae of the second stage. This species expresses a preference for the Northern exposure in this area, and migrates towards the exposure Is for the summer, and also two periods of laying spring and autumnal. The greatest number of eggs is noted in autumn, but the top can take place in summer (Balachowsky and Mesnil, 1935), stress that the laying is of $800-1500$ eggs. It has two types of mortality: a mortality natural, very important in the mobile larvae not protected by a carapace, and physiological in the adult females after the completion of the laying.

Table 1 : Dynamics populations of C.rusci on fig tree at Médéa.

\begin{tabular}{|c|c|c|c|c|c|c|c|c|c|c|c|c|c|}
\hline & \multicolumn{2}{|c|}{ L1m } & \multicolumn{2}{|c|}{ L1† } & \multicolumn{2}{|c|}{ L2t } & \multicolumn{2}{|c|}{ L2m } & \multicolumn{2}{|c|}{$\mathrm{Jt}$} & \multicolumn{2}{|c|}{$F$} & \multirow{2}{*}{ Total } \\
\hline & $\mathrm{nb}$ & $\%$ & nb & $\%$ & $\mathrm{nb}$ & $\%$ & $\mathrm{nb}$ & $\%$ & $\mathrm{nb}$ & $\%$ & $\mathrm{nb}$ & $\%$ & \\
\hline 19.11 .08 & 1090 & 93,08 & 0 & 0 & 22 & 1,8 & 0 & 0 & 36 & 3,07 & 23 & 1,90 & $11 / 1$ \\
\hline 25.11 & 0 & 0 & 0 & 0 & 92 & 20,1 & 0 & 0 & 136 & 29,80 & 228 & 50 & 456 \\
\hline 03.12 & 0 & 0 & 0 & 0 & 11 & 5,3 & 0 & 0 & 6 & 2,90 & 189 & 91,70 & 206 \\
\hline 09.12 & 0 & 0 & 0 & 0 & 40 & 55,5 & 0 & 0 & 23 & 31,90 & 9 & 12,50 & 72 \\
\hline 17.12 & 0 & 0 & 0 & 0 & 22 & 40,7 & 0 & 0 & 24 & 44,40 & 8 & 14,80 & 54 \\
\hline 25.12 & 300 & 88,50 & 0 & 0 & 13 & 3,8 & 0 & 0 & 15 & 4,40 & 11 & 3,20 & 339 \\
\hline 31.12 & 0 & 0 & 0 & 0 & 10 & 12,3 & 0 & 0 & 14 & 17,20 & 57 & 70,30 & 81 \\
\hline 07.01 .09 & 0 & 0 & 0 & 0 & 5 & 41,6 & 0 & 0 & 4 & 33,30 & 3 & 25 & 12 \\
\hline 15.01 & 0 & 0 & 0 & 0 & 11 & 52,3 & 0 & 0 & 7 & 33,30 & 3 & 14,20 & 21 \\
\hline 20.01 & 0 & 0 & 0 & 0 & 5 & 26,3 & 0 & 0 & 13 & 68,40 & 1 & 5,20 & 19 \\
\hline 29.01 & 0 & 0 & 0 & 0 & 8 & 44,4 & 0 & 0 & 6 & 33,30 & 4 & 22,20 & 18 \\
\hline 04.02 & 0 & 0 & 0 & 0 & 0 & 0 & 0 & 0 & 5 & 62,50 & 3 & 37,50 & 8 \\
\hline 12.02 & 0 & 0 & 0 & 0 & 0 & 0 & 0 & 0 & 10 & 100 & 0 & 0 & 10 \\
\hline 18.02 & 0 & 0 & 0 & 0 & 1 & 6,6 & 0 & 0 & 3 & 20 & 11 & 73,30 & 15 \\
\hline 26.02 & 0 & 0 & 0 & 0 & 1 & 100 & 0 & 0 & 0 & 0 & 0 & 0 & 1 \\
\hline 04.03 & 0 & 0 & 0 & 0 & 0 & 0 & 0 & 0 & 3 & 50 & 3 & 50 & 6 \\
\hline 18.03 & 0 & 0 & 0 & 0 & 0 & 0 & 0 & 0 & 0 & 0 & 0 & 0 & 0 \\
\hline 26.03 & 35 & 89,70 & 0 & 0 & 1 & 19,20 & 0 & 0 & 0 & 0 & 4 & 10,20 & 39 \\
\hline 01.04 & 0 & 0 & 0 & 0 & 0 & 0 & 0 & 0 & 1 & 9,09 & 9 & 81,80 & 11 \\
\hline 30.04 & 0 & 0 & 0 & 0 & 0 & 0 & 0 & 0 & 0 & 0 & 0 & 0 & 0 \\
\hline 07.05 & 0 & 0 & 0 & 0 & 0 & 0 & 0 & 0 & 0 & 0 & 13 & 100 & 13 \\
\hline 11.05 & 0 & 0 & 0 & 0 & 0 & 0 & 0 & 0 & 1 & 8,30 & 11 & 91,60 & 12 \\
\hline
\end{tabular}

$L_{1} m: 1^{\text {st }}$ mobile larvae $; L_{1} f:$ fixed larvae $; L_{2} f: 2^{\text {sd }}$ stage female larvae $; L_{2} m: 2^{\text {sd }}$ stage male ; Jf :Young female ; $f$ : mature Female 
Agric. Biol. J. N. Am., 2012, 3(5): 208-212

Table,2: Distribution cardinal of $C$,rusci on Fig tree

\begin{tabular}{|c|c|c|c|c|c|c|c|c|c|c|c|c|c|c|}
\hline & \multicolumn{2}{|c|}{ L1m } & \multicolumn{2}{|c|}{ L1f } & \multicolumn{2}{|c|}{ L2f } & \multicolumn{2}{|c|}{ L2m } & \multicolumn{2}{|c|}{ Jf } & \multicolumn{2}{|c|}{$\mathrm{F}$} & \multicolumn{2}{|c|}{$\mathrm{M}$} \\
\hline & $\mathrm{nb}$ & $\%$ & $\mathrm{nb}$ & $\%$ & $\mathrm{nb}$ & $\%$ & $\mathrm{nb}$ & $\%$ & $\mathrm{nb}$ & $\%$ & $n b$ & $\%$ & $\mathrm{nb}$ & $\%$ \\
\hline Nord & 1035 & 72,60 & - & - & 63 & 24,40 & - & - & 103 & 32,2 & 354 & 75,10 & - & - \\
\hline Sud & 300 & 21,05 & - & - & 77 & 29,80 & - & - & 73 & 22,9 & 19 & 4,30 & - & - \\
\hline Est & - & - & - & - & 53 & 20,50 & - & - & 72 & 22,5 & 16 & 3,80 & - & - \\
\hline Ouest & 90 & 6,30 & - & - & 65 & 25,10 & - & - & 71 & 22,2 & 82 & 17,40 & - & - \\
\hline & 1425 & 100 & & & 258 & 100 & & & 319 & 100 & 471 & 100 & & \\
\hline
\end{tabular}

Table.3: Oviposition average of C.rusci on Fig tree

\begin{tabular}{|c|c|c|c|c|}
\hline & \multicolumn{2}{|c|}{ Femelles } & \multirow{2}{*}{ eggs } & \multirow{2}{*}{ Average } \\
\hline & preoviposition & oviposition & & \\
\hline 19.11 .08 & 36 & 0 & 0 & 0 \\
\hline 25.11 & 136 & 19 & 14455 & 760.70 \\
\hline 03.12 & 6 & 3 & 1273 & 42430 \\
\hline 09.12 & 23 & 15 & 5640 & $4<4,00$ \\
\hline 17.12 & 24 & 1 & 157 & $\begin{array}{l}004 \\
157\end{array}$ \\
\hline 25.12 & $\begin{array}{l}<4 \\
15\end{array}$ & 17 & 2223 & 130 \\
\hline 31.12 & 14 & 39 & 3181 & 81 \\
\hline 07.01 .09 & 4 & 0 & 0 & 0 \\
\hline 15.01 & 7 & 0 & 0 & 0 \\
\hline 20.01 & 13 & 0 & 0 & 0 \\
\hline 29.01 & 6 & 30 & 1200 & 40 \\
\hline 04.02 & 5 & 1 & 7 & 7 \\
\hline 12.02 & 10 & 0 & 0 & 0 \\
\hline 18.02 & 3 & 10 & 600 & 60 \\
\hline 26.02 & 0 & 0 & 0 & 0 \\
\hline 04.03 & 3 & 0 & 0 & 0 \\
\hline 18.03 & 0 & 2 & 270 & 135 \\
\hline 26.03 & 0 & 6 & 930 & 155 \\
\hline 01.04 & 1 & 8 & 1600 & 200 \\
\hline 30.04 & 0 & 0 & 0 & 0 \\
\hline 07.05 & 0 & 10 & 3680 & 368 \\
\hline 11.05 & 1 & 11 & 5445 & 495 \\
\hline
\end{tabular}

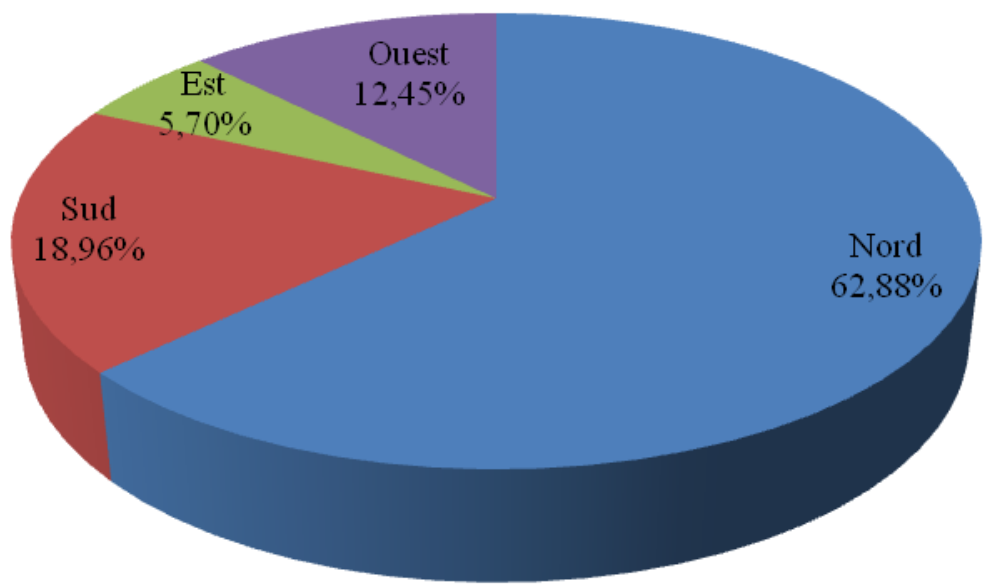

Fig 3: Spatial distribution of mealybug on the fig tree in the région of Médéa 

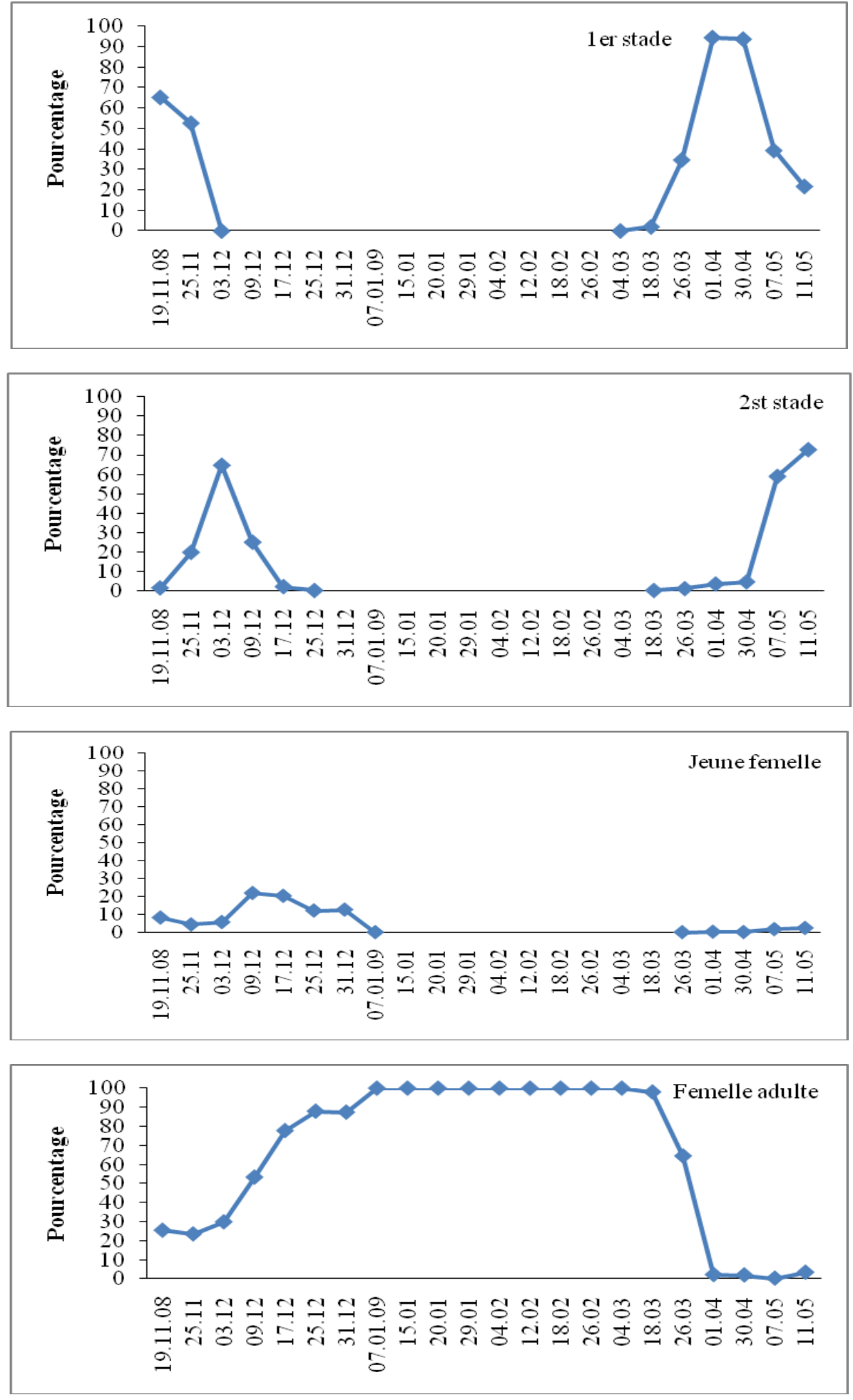

Fig 1 - Evolution of the different stages of Ceroplastes ruscii on fig tree in the region of Medea 


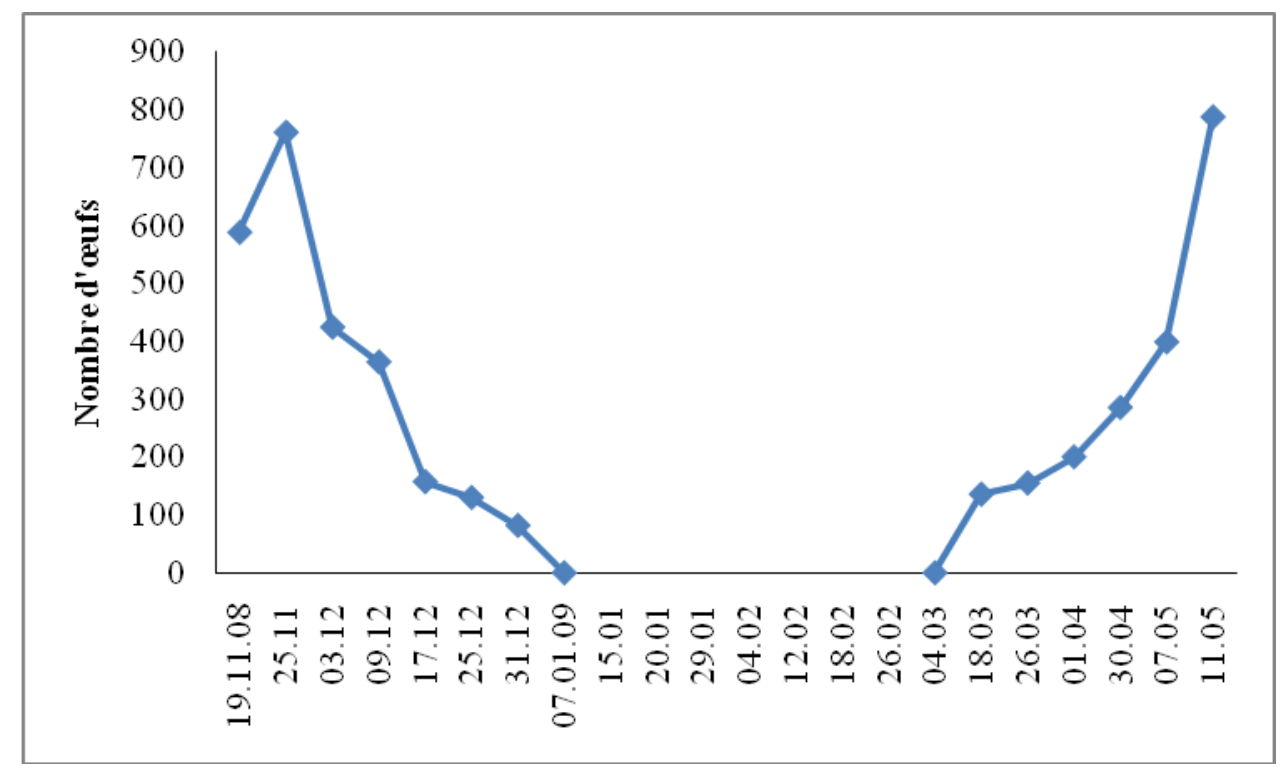

Fig 3 : Average fertility of de Ceroplastes rusci on the fig tress in the region of Médéa

\section{CONCLUSION}

The results collected between on November $19^{\text {th }}$ and on May $11^{\text {th }}$, show that C.rusci expresses two generations per year in the area of Médéa: a spring generation and autumnal. The Northern orientation of the tree seems to be the preferential place for the populations of C.rusci. The hivernation is carried out at the stage young female and adult female with which the larvae with the $2^{\text {nd }}$ stage female are associated. This work will be supplemented by a study relating to the biology and the evaluation of the pressure of the parasites hymenopterous in particular Tetrastichus ceroplastae

\section{REFERENCES}

Abel Abounasser, S.D - Insects harmful in Lebanon. Ed.Serv.entomol.quar.agric., Lebanon $16 p$

Balachowsky A.S. and Mesnil L., 1935 - Harmful insects with the crop plants. Their manners, their destruction. ED. Mery, Paris, volume 1:627 p

Benassy C. and Free E., 1974 - On the ecology of Ceroplastes rusci L. (Homoptera-Lecanidae) in the Maritime Alps. Year. Zool. Ecol. Anim., 6 (1): 11-39

Benfatto D, 1983 - Observation on the chemical control of phytophagous of citrus fruits, Ceroplastes rusci L. (Hem: Coccoidea). Estr. Year. Inst. Sup. Agric., 1516: $126 \mathrm{p}$

Bodenheimer H.S., 1951 - Citrus entomology in Middle East. ED Dr. Junk' S Gravenhage nitgevery: 633 p.

Bonnemaison L., 1953 - Animal parasites of the crop plants and the forests. ED Seta, Paris: $568 p$
Hamadou H., 1989 - Contribution to the estimate of the damage of Geotrogus deserticola (Collar: Scarabeïdae) on corn with Médéa: test of effectiveness of some insecticides. Mém.Ing.Agron., INA (Algiers): $54 \mathrm{p}$

Risbec J., 1960 - the entomological fauna of the cultures in Senegal and French Sudan. ED. Tr. lab. entomol. sect. Sudanese Recher. Agric.: 222-223.

Silvestri F., 1934 - Compedio di entomologia applicata. ED. Stab. Tip. Bellavista, Leaves special, 6: 761-766 